\title{
Toward a Discovery of Truth in the Study of Verbal Meaning
}

\author{
By Marija Liudvika Drazdauskiene*
}

\begin{abstract}
The question in focus is the reliability of the analysis of imaginative literature for truth or referential meaning and the validity of the method. The paper is a work in stylistics supported with basic references. While truth in language is a matter of propositional logic, truth in literature is a side question, as the notion of truth in literature is gleaned from evaluative meaning in the analysis of which intuition and subjective opinion matter. Yet the assessment of truth in literature is subject to faultless logic and credible literary material. What is methodologically new belongs to recent studies of style and encompasses qualitative analysis and a functional method derived from a study of uses of language. The analysis is based on the method of close reading and includes Method II described by Stephen Ullman. This method focuses on sense effects and traces them down to the devices that produce them; it is thus in line with recent linguistic theory. Other methodological principles include the concept of three levels of meaning in stylistics - the semantic, the metasemiotic and the metametasemiotic - and the criterion of relevance in the analysis. Research material in overview reveals how representation of routine matters, science and scientists, the popular press, and people and places are evaluated and what this signifies to the analyst. It is found that evaluation in the above descriptions is credible as it can be confirmed by experience, which ultimately means that referential truth can be gleaned in fiction analytically, yet can be confirmed only experientially or logically. The method based on the tracing of evaluative meaning is viable, but the experiential criterion is temporary. Representation in the novel under analysis has national and cross-cultural significance through universal and culturally shared evaluative senses.
\end{abstract}

Keywords: Evaluative meaning, Imaginary truth, Levels of meaning, Referential truth, Significance

\section{Placing the Research Task in Stylistics}

There is much agreement on the interrelatedness of language and culture. There is less agreement on the point of how language records human history and experience, especially on the question of how this can be deciphered. The first question in this paper is the question of approach and method, and the second is the value of the method. The study has been done within the framework of stylistics, because stylistic analysis envisages the broadest and the most detailed treatment of a verbal object, as it is based on interpretation. Stylistic analysis focuses on the active use of language irrespective of whether it is routine or literary language, and so stylistics can render results of current interest.

From the inception of stylistics, imaginative literature featured as an unquestionable resource (Bloomfield 1975-1976), and stylistics has naturally been "the central discipline of literary study" (Stockwell 2006). Individual styles were assumed to be a major goal in style studies (Milic 1969) probably because meaning in language "that is above its material content" is accessible and is wholly "the subject of stylistics" (Jakobson 1970). Style studies had been and have remained based on semantics because semantic networks indicate relations

*Professor, Wszechnica Polska, Poland. 
between social behaviour and linguistic forms ${ }^{1}$. Moreover, interpretation in stylistic analysis warrants an access to cognition and explanation ${ }^{2}$, two major goals of humanitarian studies.

\section{The Question of Truth and Language}

The Question of Truth and Language has a broader range than can be encompassed in this paper. It has been studied essentially by Bertrand Russell (1965), who found that truth is defined by non-linguistic experience and logical deduction (Russell 1965: 156, 214). The experience has to be immediate, while logic must be basic and faultless. Considering that language serves "three purposes, (1) to indicate facts, (2) to express the state of the speaker, and (3) to alter the state of the hearer" (Russell 1965: 194), Bertrand Russell thought that sentences indicate facts and express the state of the speaker (p. 19). In general, this makes them significant as opposed to words to which the concept of meaning applies (p. 158). As opposed to "strings of words that are nonsense", sentences signify propositions as a rule and are reliable in recording experience, as basic and experiential propositions cause no problems of falsehood. "The problem of truth and falsehood has to do with 'indication' ... truth and falsehood apply primarily to beliefs, and only derivatively to sentences as 'expressing' beliefs" (p. 203). It is sentences like "I think it will rain" or "I hope you'll manage", or propositional attitudes, that are problematic in logic, and falsehood can slip into them. A logical conclusion is that truth resides in speech, which rests on basic propositions, but this is exactly the opposite of what is relevant in imaginative literature. In imaginative literature, which rests on macro and micro fictitious images, evaluative meaning is primary, and reality is accessible exactly through this meaning.

\section{Evaluative Meaning in Imaginative Literature}

The focus in the analysis of imaginative literature, while also seeking realistic truth, has to be on evaluative meaning (Barthes 1989, Drazdauskiene 2008). Following the practice of Jeffrey Leech and Mick Short (2007), this concept can be detailed. Katie Wales (1991) refers to Palmer for evaluative meaning and finds it "akin to emotive meaning," which identifies with "words which affect our emotions because they have connotations of approval and disapproval" (Wales 1991: 160). Katie Wales specifies further by saying that "in everyday language much of what we say is not a statement of fact, and conceptual meaning is not

${ }^{1}$ Cf.: "... as the lexicogrammatical system realizes the semantic system, the semantic system realizes the behavioural system, or the social semiotic". And, in other words: "... if ... we have identified a set of options in meaning, ... we have also to show, first, how this set of options in meaning realizes an aspect of the social system and, secondly, how it is in turn realized in the lexicographical system" (Halliday 1978: 42, 43).

${ }^{2} \mathrm{Cf}$.: "An account of the process of interpretation is thus the key to understanding of the signsituation, and therefore the beginning of wisdom" (Ogden and Richards 1923/1960: 50). 
necessarily paramount. We are continually assessing situations, people, others' speech". Making judgements about evaluative meaning in literature, the analyst becomes vulnerable on the point of truth in his statements because evaluative meaning is assessed on the basis of 'expressing' attitudes and beliefs. Although the truth of reality is not perceived in imaginative literature as the truth based on experience and basic propositions, judgments of evaluative meaning from which glimpses of referential truth derive in imaginative literature have to be trustworthy propositions that do not contradict experiential logic. Analytical judgments have to be sound and based on the data of delicate stylistic analysis because cognitive meaning in literature can be gleaned only in its most delicate aspects (Drazdauskiene 2002).

Evaluation in imaginative literature is not only emotively marked figurative meaning. Evaluation features in any instance of exchange in fiction. A relevant example would be an episode of an exchange between two sisters, one of whom comes on an invitation from the other to a party, from the first novel by Margaret Drabble:

... I rang. This must have been the right thing to do, because Louise herself opened the door, and had obviously been standing in the hall to do so. It was such a shock to see her that I had nothing to say.

She too looked taken aback, though not in any obvious way: "Why, Sarah", she said very loudly, "how enchanting to see you, how very kind of you to come".

"How very kind of you to ask me", I said.

"It must be months since I last saw you".

"It is. It was September".

"Oh yes, September. It was at my wedding, wasn't it?"

"That's right. At your wedding".

"It seems a long time ago".

"Yes, it does, doesn't it?"

We then paused a little to take breath in this scintillating exchange. She was looking very marvellous by any standards, wearing a kind of creamycoloured wool dress in a curious towelling texture, ... .

Margaret Drabble, A Summer Bird-Cage. Penguin 1967: 117-118

Evaluation is quite strong and obvious here because irony is assumed by the author, "in this scintillating exchange", and the overemphatic tone of Louise, who is the hostess, had been hinted at by the author earlier: "I had nothing to say", "She too looked taken aback" and "she said very loudly". The evaluation is overt, ironical and leaves no room for misinterpretation of its sense. However, as the author's evaluation sinks in, the reader feels like turning back to the exchange to evaluate it on his own. On second reading, the utterances in the exchange appear more obviously ironic: the utterances indicate an overdone sound because they are unnatural between two sisters. This is a very delicate point in evaluation where the reader identifies with the author's implied sense on how overdone the 
exchange was. This further testifies to the culture which the reader shares with the author in his experience of understanding. If overdone utterances were culturally natural in a British context, the reader's perceived sense would be wrong. It is the delicate points like this that confirm or overrule the reader's literary understanding. There usually is consecutiveness in cultural overtones in imaginative literature because its cultural context would be confusing, destroyed or unidentifiable without it. Even when cultural representation is consecutive in its overtones, some manly irony may escape or confuse a foreign woman reading such works as, What's Fun Got to Do with It? An Anthology of American Humor, edited by Helle K. Thomson and Jacob D. Eichler, or The Sell Out by Paul Beatty.

Evaluative meaning may be less pronounced in imaginative literature. Consider, for example, a speaker's impression of the termination of a telephone talk with her sister, from the same novel by Margaret Drabble:

"Where are they at the moment?"

"Having tea".

"Oh, I see. Well, you'd better go and join them".

"See you", said Louise, and rang off. Not for her a diminuendo of "Well" it's been nice hearing you, and you too, thank you for ringing, good-bye, good-bye, good-bye, bye then, see you, "bye then", off.

Margaret Drabble, A Summer Bird-Cage. Penguin 1967: 13

The sense of the speaker's displeasure at the abrupt end of the conversation is obvious in the words, "Not for her a diminuendo ...", because protracted ends of conversation have a cross-culturally shared sense. That is to say, we share the cultural assumptions and attitudes in this episode. If we could not share them, that is, if an abrupt end of conversation were the norm for us, we could not understand the speaker's resentment in this situation. Shared cultural and psychological understanding in fictional situations like this depends entirely on the correct perception and interpretation of evaluation.

Evaluative meaning in imaginative literature has a broad spectrum. It includes implicature in instances as vague as the one quoted above, connotations of formal and informal words, and of evaluative words specifically, as well as all other senses in uses of language such as overstatement and understatement, simile, metaphor, irony, and humour ${ }^{3}$. However, the analysis in the present paper is not a process of noting and picking apart evaluations. It is rather a stylistic analysis of the complete text of a novel with tolerable inaccuracies. While encompassing the general sense of the work, concrete episodes are re-read and appreciated in their immediate co-text and in the complete work. The purpose of the analysis is not specifically "an attempt to find the artistic principles underlying a writer's choice of language", which are thought to be an attempt in "every analysis of style" (Leech and Short 2007: 60). A few observations on the author's artistic accomplishment have been made, but stylistic analysis is

${ }^{3}$ The reference for the concepts of these units are A Dictionary of Stylistics by Katie Wales (1991) and Professor Leech's early study, A Linguistic Guide to English Poetry (1969). 
partial in this respect. The purpose instead has been to focus on and interpret evaluative meaning in fictitious and cultural contexts. Methodologically, the paper utilizes several methods in stylistics.

\section{Methodological Principles}

The basic methodological idea comes from the most general and tested methods of stylistic analysis. The paper has profited from Method II described by Stephen Ullmann (1973: 85), which focuses on sense effects and traces them down to the devices that produce them. The preference for this Method II rather than Method I, which focuses on the devices and interprets their effects, is motivated by two reasons: First, Method II is consistent with the process of the perception of a literary work, with the general principles of stylistic analysis of concrete works, and is in line with recent linguistic theory ${ }^{4}$. Second, Method II as described by Stephen Ullmann orientated the direction of thought throughout the analysis.

Technical decisions and choices in the present analysis owe to Michael Halliday's work (1973), in which he solves the question of relevance in stylistic analysis. As the quotations from fiction briefly analysed above indicate, the stretch of the text which is required to trace and interpret evaluative meaning extends between a fragment of the text and a word, while the sentence/utterance and the phrase/word are key units.

Analytical reasoning and statements of meaning were oriented by the concept of three levels of meaning in stylistics: the semantic (literal meaning), the metasemiotic (overtones of meaning) and the metametasemiotic (the ultimate verbal senses) (Akhmanova 1972: 53-60). Research of the present author (Drazdauskiene 1992: 64-65) testified that the semantic and metasemiotic levels of meaning are language-bound. The metametasemiotic level is the ultimate level on which interpretative generalisations relate minimally to the language of the text. In further generalisations, the analyst parts with the direct relation to the text and reasons in artistic, cultural or semiotic concepts. Awareness of these distinctions in the levels of meaning was especially useful in the present study deliberating on language, literature and culture.

Henry H. Widdowson's (2010) critical analytical appreciation of the tenets of Systemic/Functional linguistics and critical discourse analysis could not be employed because uses rather than functions of language were the background research. Uses of language encompass speech in process and its purport in any stretch of speech, which would identify with Widdowson' pragmatic purpose. A pragmatic purpose, in the present understanding, would identify with the aesthetic purport in imaginative literature and with a property of the metacommunicative use of language, which represents all imaginative literature ${ }^{5}$. The

\footnotetext{
${ }^{4} \mathrm{Cf}$.: "All language functions in contexts of situation, and is relatable to those contexts. The question is not what peculiarities of vocabulary or grammar or pronunciation can be directly accounted for by reference to the situation. It is which kind of situational factor determine which kinds of selection in the linguistic system" (Halliday 1978: 32).

${ }^{5}$ In the present paper, it was also useful to bear in mind the emotive use of language originally singled out by Roman Jakobson (1960) for the mere division of labour.
} 
present author's study of uses of language, explained the origins of the textual function, which were missing in the original work (Halliday 1976: 28-30, cf. pp.18-25) and which was found to emerge from the phatic and the referential uses of language (Drazdauskiene 1992: 67). In the present as in earlier analysis, any text was treated as an item of discourse and observed how actual units of the text functioned depending on the purpose of the text as a discourse unit. This helped escape the entanglement with constraints on the tenets of Systemic/ Functional linguistics considered by Henry G. Widdowson (2010). In the present analysis, the reasoning was not bound to systemic relations in language. The leading concept was the idea of meaning governing all the units of language in contexts and that of hierarchical interdependence of the units.

As Lesley Jeffries and Dan McIntyre (2012: 170-190) suggest, stylistic analysis can draw on several methods, which I, in fact, have done. These authors find two major methodological distinctions - qualitative and quantitative methods, which the present author took into consideration. The present analysis has been qualitative as the text of the novel, The Pure Gold Baby, by Margaret Drabble has been studied consecutively. The analysis was based on close reading and disciplined by the principles of the methods briefly explained above. The major research question (Jeffries and McIntyre 2012: 171-172) was what can be traced of contemporary man and his culture in the novel under analysis and how this is conveyed by the author. Minor research questions were how evaluative meaning conveys (directly or indirectly) emotive and sociocultural senses and how evaluative meaning relates to the verbal expression, i.e. whether there is any formal verbal distinction in the representation of, for example, people and objects, attitudes and actions, events and emotions.

\section{The Range of the Research Task}

In the present project ultimately envisaging ideas of social culture and native character, literary studies may be more productive than sociological merely because of the delicacy of insight that style studies require and of the variety of attitudes and relations represented. A recent equivalent and major study of sociocultural character in French (Robert Crawshaw and Kerin Tusting 2000, Crowley 1991) focuses on texts of all genres in current usage. Choosing imaginative literature as the material, the study is likely to be gainful when it is based on stylistic analysis of relevant works and done by a functional method. However, seeking a discovery of truth in a study of imaginative literature and focusing on semantic networks to pursue the significance of evaluative meaning, the concept of truth becomes relative: neither statements that indicate facts nor their logical equivalents have truth value for imaginative literature (Miller 2002: 16-20). Nothing but implications have the credibility of truth in literary representation, irrespective of whether they are called connotation ${ }^{6}$ (Barthes

${ }^{6} \mathrm{Cf}$.: "We have again come to realise that literature is not realistic: it can only "imprint" reality through the medium of language, while language itself relates to reality through the social convention rather than through "nature". /.../ In any case, when "reality" is elevated to the level 
1989: 282-283) or evaluative and suggestive effects (Widdowson 1992: xii) or "the expression of alternative values" (Widdowson 1992: 8). What we can hope to discover in a study of literary language is truth which is not a fact, but rather the truth which is gleaned from delicate implications in literature that suggest relevance to and identity with what is reality ${ }^{7}$ in common human understanding.

The research which is reported here has not been designed to produce a definitive study. It has been known that "attempts to characterize a culture by its language are full of pitfalls which few have escaped". As this "cannot be entirely ruled out" (Bloomfield 1975-1976: 274), attempts have been made to look into evaluative meaning in as much as it is implicative of culture and generalise on it taking responsibility for research findings and for the credibility of generalisations. It has been assumed that reality is the physical nature of which we are aware and acknowledge its cognition, including the experience of events in it. This, then, includes culture as customs and outwardly perceivable patterns of behaviour. As has been mentioned above, judgments of evaluative meaning and statements of how reality can be gleaned in imaginative literature are subject to logical propositional tests as a reliable resort.

\section{Analysis}

The novel The Pure Gold Baby by Margaret Drabble is a multi-layered narrative about a girl and her single mother living in a modern urban environment, which, judging by the place names, is London. Their story is told by a feminine narrator of the same milieu with distinct asides in the form of literary phatic ${ }^{8}$.

of sacred value (so far ideologies of progressive directions have distinguished themselves thus), it happens to be discovered that literature is only language, and a secondary language in addition, collateral sense, so that it is related to reality only through connotation rather than denotation" (Barthes 1989: 282-283) (Translation by MLD), cf.: Riffaterre 1982.

${ }^{7}$ I have not investigated the modern concepts of reality in physics and philosophy, although I have been familiar with the modern conceptions in brief (Rovelli 2015, Cain 2016, Six Physics Equations 2016, Baraniuk 2016, Evans 2016, Orwig 2016, Hinzen 2007, Jackendoff 2012).

"Literary phatic" is the term I have chosen for interpolations in the first person singular or plural into the literary narrative, which comment, disconnectedly, on the author's own mainline narrative. For example: "I have taken it upon myself to tell this story, but it is her story, not mine, and I am ashamed of my temerity" (p. 14), "My husband and I didn't really see eye to eye about education, but he allowed me to make the decisions. He was, I sometimes thought, too busy with his work, ..., to notice much of what was happening on the domestic front, and that suited me quite well. But happily that is not part of this narrative" (p. 52), "It (the wedding) was for us, a jolly adult affair, sealed on a sunny Saturday morning in October in Islington Town Hall. This prominent Neoclassical edifice on Upper Street was not then the fashionable and well-restored New Labour venue that it was to become: it was a hotbed of revolt, with radical slogans ... scrawled in bloody paint and strung in homemade banners across its pillared façade. / Or were those banners hung a little later than Jess's wedding? I forget the sequence. When you live in an area for many decades, the dates blur and merge; it's hard to remember precise dates. You remember the feel of ebb and flow, but it's easy to get the dates wrong" (p. 62), "It was a real treat and we all missed it when it closed down (The Finsbury Park Astoria belongs to some kind of extreme religious sect these days, it's far more way out than the Finsbury Park mosque) I can't remember which cinemas took over as the children grew up - did we have to go down to Upper Street and the Angel? I can't remember" 
Both the girl Anna and her mother Jess are assessed as being of sterling quality: the girl for her essential peaceful grace, who provoked good behaviour even from the irresponsible and ... absconding (p. 44) and the mother for her modest and unfaltering, unfailing dedication to her chosen field, anthropology, (She remained pure gold and told no lies, p. 47) and, mostly, for her maternal feelings and attachment, which had been "proleptic" as conceived in advance, on her single expedition to Africa. Although each infant was thought by them to be "born pure and new and holy: a gold baby, a luminous lamb" (p. 46), Anna was "the pure gold baby" (p. 147), so pure that Jess sought a better word for her deficiencies than "the dignified phrases", "special needs" and "learning difficulties" (p. 146).

As a work of fiction, the novel, The Pure Gold Baby, is an intellectual evaluative narrative. Its emotive charge is subdued and delicate, partly hidden in evaluations. The analysis has to be very accurate because the line between imaginary truth and realistic truth is very thin. The analyst's assessment is somewhat simpler at the points of literary phatic, but even these interpolations are marginal as some are more and some less integrated into imaginary representation.

Apart from Anna, the novel centres on her mother Jess, the narrator, and their company or people in the vicinity. The focus is on how the main actors see themselves in life. Intellectual philosophical digressions keep up the selffocused line of narrative and involve the reader in deliberations on man's consciousness, his moral dicta and responsibilities.

Given no exposition as a specific section for an introduction of the actors, the opening pages of the novel lay out scenes for deliberation of how maternal feelings can be conceived: surrounded by a "poor, peacable and unaspiring tribe" in Africa, Jess is represented to observe native children with toe deformities, "agile and busy on the water" playing a simple game of stones. She was to remember the simple children, playing beneath the vast African sky (p. 3), with their simple stones and simplified toes (p. 3) long past. From this first scene of her single anthropological expedition to Africa, she took home with her a treasure, a stone with a hole in the middle, a stone age stone that could make rain (p. 3). This simple keepsake signifies the permanence of Jess's maternal feelings confirmed by the narrator: Jess was to keep the rain stone with her all her life (p. 4).

This artistically integrated exposition outlines the spiritual development of the story in the novel. It is a very well-wrought beginning that reaches over to the very end. Although there is a scientific hint at Jess's not knowing of the origin of the children's deformed toes, which was "well documented" and well known to her colleague Guy Brighouse, later to become her scientific adviser, this detail is part of imaginary truth. It is only as part of the artistic design that it encourages

(p. 131), "In the restaurant just off Queen Square, Raoul and Jessica talked about the Lebanon and the Sudan and Mongolia (We don't use those definite articles now) They ate fusilli and farfalle and drank a bottle of San Pellegrino" (p. 201).

The term "phatic" is the same Bronislaw Malinowski's term (1923/1960) which meant verbal exchange or "gossip" accompanying "mere manual work", which does or does not create "a common sentiment" among native Islanders of the Pacific or participants in small talk in European drawing-rooms. Later, the term "phatic" came to mean the contact maintenance use of language where this term covers not only small talk but also any shorter or longer utterances which ensure verbal contact in conversation and in writing (Drazdauskiene 1992). 
deliberation on the knowledge possessed by scientists. This is a fitting hint as this line in the novel continues both as part of fictitious and realistic truth. In the context of the novel, children's diseases, women's practices, science and scientists are mentioned by names, and sometimes by terms (pp. 12, 45, 49, 23-25, 26, 30$31,45)$. The names themselves make only fictitious representation tougher and less emotive. Notions of referential truth begin being formed when the persons named and their engagements appear in evaluating descriptions. For example, the ethnographer and photographer presented expressively remains only a fictitious image, a man who might have been chosen by Jess as her partner. Anthropologists who are characterised amid the features of the dismissed Professor, Anna's father, are given realistically relevant evaluations.

For example, children's diseases are deliberated (pp. 23-25) as Anna's condition by birth becomes precarious. Although her diagnosis is not final, hints at it are made by mentioning discoveries related to Down's syndrome - (not that Anne was thought to have Down's syndrome) (p. 29), the testing of certain genetic diseases, the positive and negative effects of vaccination (pp. 23-24), and other related matters. Such briefs of diseases are made while mentioning that vaccination was hotly debated by a new generation of highly educated mothers who wished to apply intelligence as well as instinct to maternity (p. 14) and concluding with shocking issues on "this divisive topic". The evaluation from the mother's point of view rings the bell to the reader: the mother's attitude appears real as it compares with the culturally known sensitivities on the matter. If this parallel could not be drawn, the artistic representation would confuse and signify unrecognizable culture.

A still stronger impression of cultural affinity can be traced in an episode in which the author states that theirs was the last generation of British children to suffer routinely from such common complaints as measles and whooping cough (p. 25). The truth surfaces when the episode ends in a case of scarlet fever, which "was on the wane" and was not recognised by the doctor who never has "seen the case" (p. 25). The concluding remarks evaluate strikingly: It was diagnosed, correctly, by the elderly untrained minder of the neighbourhood, who did the Monday and Wednesday shifts at the playgroup wearing an old-fashioned flowery cotton overall. It was greeted with delight by the medical students at the Royal Free Hospital as a lucky sighting, a historic anomaly (p. 25). This episode with the students, who made a great fuss of hot and prickly little patient, could not diagnose him and were saved by an old practitioner, identifies with cases of children's diseases and child care known to all mothers in Europe. Its representation in good humour only confirms its realistic relevance: and so, a kind and a less kind view of such and similar cases assign pediatricians to the doctors of the least reliable practice, the difficulty of which mothers understand. This episode in the novel also suggests how the old and the new clash to handicap the new, which is another sensitive theme for the moderns.

Evaluative representation of scientists can be traced in similar parallels, which are less popularly known, though. Jess is characterised as "a lucky mascot," as a beginner and as very honest, "pure gold" as an experienced and unemployed anthropologist devoted to motherhood. But her thesis has a less positive 
assessment. She was "accused" to have bitten off more than she could chew in her study of witchcraft and disability in pre-imperial and post-imperial Africa (p. 42). She appears to have admitted downright omissions in her dissertation. While studying deformities of African children, she failed to include any mention of the superstitions surrounding the birth of twins in West Africa, and the heroic work of Scottish missionary Mary Slessor. She had not known that her assessor had himself specialised in Mary Slessor and twin studies. While her adviser is characterised critically as the maverick globe-trotting conference- attending fieldwork-dabbling Guy Brighouse who was nonchalant about his duties towards her (p. 42), it is said that a researcher could get away with almost anything and Jess did. The suggested conclusion is that she might have been more diplomatic in her selection of material had she known the research of her assessor. This conclusion pinpoints scientists' manipulation with management of their material and rings a very realistic note to the reading scientists and scholars. The reader even wonders whether the fictitious implication of scientific superficiality and fragmented knowledge may stir some ripples on quality in reality.

This parallel is made more obvious in another episode in the novel in which the narrator evaluates the Professor anthropologist, Jess's lover and her daughter's father, together with his professional wife: Anthropologists are a strange breed. ... some of the most celebrated anthropological narratives have curious gaps in them (p. 45). Hundreds of pages of observation and analysis appear to have been written not by anthropologists who shared the life of the studied tribes but by some of them who lived nearby in semi-comfort with his wife and a servant or two in a de-luxe tent or a mobile home, with access to the highway or the helicopter (p. 45). In this context of corrupt research, Jess is shown to doubt even the data of Lévi Strauss.

With no link to this but within the experience of the honest Jess, the story tells of a share of public mockery and opprobrium which certain academic and intellectual disciplines, certain professional occupations have received (p. 12). While as a young student, Jess saw nothing funny about anthropology, as an adult, she realised what vulgar notions were related to this field. Through allusions to Vladimir Nabokov, Jess is made to perceive what anthropology-mockery is. She finds only Saul Bellow "an honourable exception to the tradition of anthropology-mockery", even though he may have known less than Jess of "the physical continent of Africa" (pp. 12-13). The mockery, though, is not related to the superficiality of scientists. In anthropology, it is vulgarly associated with sex and concrete organs, with the nude body and the interest it can stir. Both anthropology-mockery and vulgar attitudes imply disapproval in the novel.

These evaluations realistically remind of current attitudes and practices in sciences to any practicing scientist or scholar. They are also indicative of the slanted attitudes of the public. Ultimately, the illustrated episodes read as partly fictitious and partly realistic images without any error in their truth value. The realistic truth of the state of sciences in the modern world is not far to seek in conclusion.

There are minor episodes related to science, in which popularly shared scientific knowledge or popularly and professionally evaluated illustrations in 
publications feature and are commented upon. In a personal episode of Jess, who, on hearing no suggestion at the doctor's that Anna would be a normal child, wept as she walked home with Anna in a pushchair, contemplating her and her own life to be and vowed to be "the best of mothers" (p. 20). The description of her brisk, cold way home to a lunch of boiled egg and Marmiteand-butter toast, Anna's healthy favourite, ends in the following comment: We didn't know about cholesterol then. It hadn't been invented (p. 20). Like in the episodes with children's diseases, minimal evaluations of the old and the new clash here for the reader to shake himself up to reality and smile at the missing news of 2016 of a reversed opinion on cholesterol. Literature appears to be a little slow to keep up with science news or perhaps only with a variety in science.

Several episodes in the novel focus on photographs showing people and places from other lands. Jess's initial familiarity with such photos was in the booklets her father, once in Town and Country Planning and travelling with the RAF in the Second World War, had bought in North Africa (pp. 9-10) and had given to her. Jess enjoyed the booklets: The illustrations were a wonder to her. I.../ There was interesting nudity in them on display and everything else a curious female child might wish to see (p. 10). Although she knew nothing of the production of those photographs, "these portraits were much more touchingly human than the photographs one could see in the National Geographic magazine at the dentist's" (pp. 10-11). The illustrations in the magazine were rude, intrusive and inauthentic, which indicates Jess's young, yet discerning eye for authenticity. Further on in the novel, the narrator acknowledges Jess's professional eye specifically, from which she had learned much. Jess finds even Lévi Strauss's photographs of the Nambikwara static. On this occasion, the evaluation is that you can never penetrate the photograph, they remain static, frozen, sealed ( $\mathrm{p}$. 46). The narrator finds representations on television three-dimensional, moving and better, but hurriedly adds that you can't believe anything you see on television, ever. An evaluation on television follows, and the old television is found simpler, though not as smart or as stupid as it is now (p. 46). On another occasion, Jess's dislike of Africa on television (p. 148) confirms this critical attitude. Seemingly to emphasise the stance of the professional, in one more episode in the novel, Jess is said not to want to take photographs at all and here her scholarly mind shows: "Snapping birds and people wasn't scholarly, it was National Geographic" (p. 61). These evaluations of withheld criticism move the reader to recognise scientists' known reluctance to read and publish in the popular press, which degrades and distorts scientific knowledge.

This novel moves the reader to extralinguistic experience by discovering the stories behind the proper names. The explorer Livingstone recurs and is represented in brief comments. The Scottish explorer Mungo Park is more episodic but encourages curiosity as do Rodin's sculptures and his life, in the Museum. The novel encompasses a few literary allusions with inroads into a few texts through Wordsworth (pp. 90, 122, 146), John Keats (pp. 56, 64, 124), William Blake (p. 62), Jane Eyre (p. 120), Macbeth (p. 141), Villon and Dante (p. 141), in addition to the specific and longer references to Vladimir Nabokov and Saul Bellow (pp. 12-14). 
Place names in London excite similar curiosity, especially given that they recur throughout the novel. London is touchingly evaluated while representing its post-war days: The bomb damage of London was at last being very slowly repaired, with spirit if not always with style, and the streets of the late fifties and early sixties were full of promise and change and hope (p. 9). This tender and insightful evaluation touches upon the reminiscences of many a resident of European post-war capitals when the spirit was clean and honest and hopes high.

A still richer episode is that of the post-war SOAS - School of Oriental and African Studies. The seventeen-year-old Jess's enchantment with this school is part of imaginary truth, but its evaluative descriptions imply referential truth. This school situated "in the heart of academic Bloomsbury" (p. 8), enchanted Jess not only by the acronym of its name. It was an absolute novelty to her: She knew nothing of Bloomsbury or of London when she arrived there from her provincial home in white-white-white Middle England (p. 8). The implication of Jess's middle class status and of her youthful ignorance of the capital in the 1950s-1960s, would be only imaginary truth but for the reiterated presence and status of other young people in the following lines: (London in those days was full of young people from the regions who knew nothing of Bloomsbury.) SOAS was a sea of adventure, of learning, of cross-cultural currents that swept and eddied through Gordon Square and Bedford and Russell Square and along Great Russell Street (p. 8). The image of ignorant young people in the literary and academic district of London is not negative: curiosity and aspiration are rather implied, as part of imaginary truth, and are confirmed in further paragraphs.

The squares and streets mentioned in the quotation above are renamed further as the square mile of colonial educational advancement, which also included the LSE and the Inner Temple (p. 9). A very vague and withheld evaluation of the importance of the provided education extends beyond Jess's fictitious enchantment with SOAS. In a further episode, names of political figures of the world, mainly from Africa, (Jomo Kenyatta, Seretse Khama, Kwame Nkrumah, ...) are given and accompanied by an evaluative line, the big names of big beasts, the stars of the savannah, the giants who would bestride the post-colonial world (p. 9). "The lesser people" from India, South Africa, Indonesia and Burma are also mentioned here, so that the epithet "big" reads not so much of those people as of big thinking of strategists in Great Britain, who educated them for the new and changing world and for loyal officials in it. However, there is no complacency or criticism of the country here. It is rather foresight and appreciation.

The ignorant young people in the Bloomsbury of the sixties also carry a positive evaluation implying trust, which was beyond their aspirations, rather than anything else. Such spirit of the young people of the 1960s can be confirmed by the experience of those remembering the atmosphere in other European capitals of the time. It was definitely more pronounced and varied in London then. Referential truth is thus intertwined with imaginary truth here, but can be discerned beyond doubt. 


\section{Discussion}

Although contextually British, the novel The Pure Gold Baby resonates, through varied evaluations, with common human experience, the more so that psychological images relate to common European human values. Despite this, the image of national identity in this novel is very distinct. It is more prominent in its second part, the material of which remained beyond the scope of this paper. A more personal story of Jess and her daughter continues in the novel to bring forth such aspects of maternity as gentleness, devotion and love, all of which have some of their peculiarly British privacy about them. Yet, the moderns have to struggle for it. Such modern problems as migrants and mosques also feature in the second part of the novel marked by the atmosphere of British tolerance.

In one of her early published interviews, Margaret Drabble said, "I write a novel when I have a problem to solve". The Pure Gold Baby, which is rich in intellectual digressions and philosophical or professional deliberations, suggests that the author had several problems to solve, among them those of single professional mothers, parental care, disabled children, families and friends, migrants, mosques and more. The author exposes these problems delicately, yet in the raw rather than solving them, except for motherhood and professional dedication, which are very individual. The other problems remain, but Margaret Drabble manages to move the reader to emotional awakening and involvement toward responsibility. My analysis has shown that referential truth can be gleaned from evaluations in this novel and can be quite credibly assessed.

\section{Conclusion}

To conclude on the first task, the method has to be assessed. Close reading and analysis, which has been done with resort to several methodological principles, was rejected long ago by Roland Barthes in his premise to structural semiotics. However, to respect literary art and to honour authors, the present approach has been trusted and found reliable. It not only reveals literature's deep and original senses, but also escapes the cul-de-sac into which Roland Barthes had run himself with his "death of the author" and has been found to be a quirk of his method (Drazdauskiene 2017). Evaluative meaning is a reliable criterion in assessing referential truth in the literature of any period. However, the premise in the present argument of the confirmation of the truth is temporary. As may have been obvious, the realistic relevance of Margaret Drabble's fictitious images and words could be confirmed while resorting to the experience of the present generation. Although this is grounded, it is doubtful that readers of two or more generations ahead would be able to assess realistic references with the same success that has been done here. On this, the method is vulnerable. Nevertheless, it confirms that truth, however discernable in fiction, can be accepted as truth only if we support our deduction with experience. It is not so with truth about feelings, emotions and attitudes. Spiritual and moral attitudes are tested intuitively and individually in reading and even when these are part of imaginary truth they bear a semblance to the realistic image of the author. 
Although the task in the present paper was set apart from the dicta of Berttrand Russell at the beginning (p. 3 above), the sense of evaluations have been confirmed with the help of historical experience, which will not be available to new generations in reading. But this is correct and, indeed, there is no other way to confirm referential truth in a work of imaginary literature. A look into a few other books of fiction complicates the matter further.

Compared with the third novel of Margaret Drabble, The Garrick Year (Belmont Books, 1971), which represents the problem of an actress torn between theatre and family, The Pure Gold Baby is greater in scope and thought. The Garrick Year is a single-line fiction which evolves in routine contexts and its analysis on the two levels of meaning is almost sufficient. Its evaluative meaning remains within personal conventional routine. The Pure Gold Baby takes all three levels of the analysis of meaning with all the references and allusions that the analyst can resort to, and with enriched conclusions. The question of referential truth, although rich in material in the latter novel, still remains a complicated question when we think of language. There is an episode in American Gods by Neil Gaiman, which questions the essence and content of the places indicated by road signs. They are called "roadside attractions" and can be confusing or ambiguous in function, but the question is about the meaning of the words: The signs for the House on the Rock were all around that part of the world: oblique, ambiguous signs all across Illinois and Minnesota and Wisconsin, probably as far away as Iowa, Shadow suspected, signs alerting you to the existence of the House on the Rock. Shadow had seen the signs and wondered about them. Did the House balance perilously upon the Rock? What was so interesting about the Rock? About the House? He had given it a passing thought, but then forgotten it (Neil Gaiman. American Gods. - Headline Publishing, 2013, p. 129). Even when we know that the referential value of names in fiction is elusive, the questions asked by Neil Gaiman are relevant to the present analysis. This is an old question of truth and reference in the philosophy of language (Hinzen, 2007). It cannot be resolved in a couple of lines here in conclusion, but it is obvious that referential truth in fiction is a many-sided problem as is the phenomenon of national identity (Crawshaw and Tusting 2000), which has been cursorily mentioned.

\section{References}

Akhmanova OS (Edn.) (1972) Linguostylistics: Theory and Method. Moscow: MGU. Baraniuk C (2016) The real reasons nothing can ever go faster than light. Retrieved from https://bbc.in/1pWxZtL.

Barthes R (1989) Literatura i znachenije (Literature and meaning). In Izbrannye raboty. Semiotika. Poetika (Selected works. Semiotics. Poetics). Moscow: Progress.

Bloomfield MW (1975-1976) Stylistics and the Theory of Literature. New Literary History. A Journal of Theory and Interpretation VII: 271-311.

Cain F (2016) What's Outside the Universe?. Retrieved from https://bit.ly/2H6WMG0.

Crawshaw R, Tusting K (2000) Exploring French Text Analysis. Interpretations of National Identity. London and New York: Routledge. 
Crowley T (1991) Proper English? Readings in Language, History and Cultural Identity. London and New York: Routledge.

Drazdauskiene ML (1992) The Phatic Use of English: Meaning and Style. Abstract of the Second Dissertation for the Degree of Doctor of Philology. Vilnius: The Institute of Information of Lithuania.

Drazdauskiene ML (2002) Literature as a Source of Cognitive Knowledge. Kalbos studijos: Studies about Languages 2: 5-13.

Drazdauskiene ML (2008) Evaluative Meaning and its Cultural Significance. Studia Anglica Posnaniensia 44: 373-389.

Drazdauskiene ML (2017) A Prospect in the Arts Viewed from the Semiotic Perspective. Retrieved from https://bit.ly/2En6st0.

Evans R (2016) Project Greenglow and the Battle with Gravity. Retrieved from https://bbc.in/1MBptps.

Halliday MAK (1973) Linguistic Function and Literary Style. An Inquiry into the Language of William Golding's The Inheritors. In MAK Halliday (Eds.), Explorations in the Functions of Language. London: Arnold.

Halliday MAK (1976) System and Function in Language. Edited by Gunther Kress. Oxford: Oxford University Press.

Halliday MAK (1978) Language as Social Semiotic. London: Arnold.

Hinzen W (2007). An Essay on Names and Truth. Oxford, New York: Oxford University Press.

Jakobson R (1960) Linguistics and Poetics. In T Sebeok (Eds.), Style in Language. Cambridge (Mass.): The M.I.T. Press.

Jakobson R (1970) The Subject of Stylistics. A lecture given in Moscow University. MS. Moscow.

Jackendoff R (2012) A User's Guide to Thought and Meaning. Oxford, New York: Oxford University Press.

Jeffries L, McIntyre D (2012) Stylistics. Cambridge: Cambridge University Press.

Leech JN (1969) A Linguistic Guide to English Poetry. London: Longmans.

Leech JN, Short M (2007) Style in Fiction. Second Edition. Harlow: Pearson Education Limited.

Malinowski B (1923/1960) The Problem of Meaning in Primitive Languages. In CK Ogden, IA Richards (Eds.), The Meaning of Meaning. London: Routledge and Kegan Paul.

Milic LT (1969) Against the Typology of Styles. In GA Love, M Payne (Eds.), Contemporary Essays on Style. Atlanta: Scott Foresmann \& Company.

Miller JH (2002) On Literature. London and New York: Routledge.

Ogden CK, Richards IA (1923/1960) The Meaning of Meaning. London: Routledge and Kegan Paul.

Orwig J (2016) Two most dangerous numbers in the universe are threatening the end of physics. Retrieved from https://ind.pn/2ElZogm.

Riffaterre M (1982) L'illusion référentielle (The referential illusion). In R Barthes, L Bersani, P Hamon, M Riffaterre, I Watt (Eds.), Litérature et réalité (Literature and reality). Paris: Editions du Seuil, 1982.

Rovelli C (2015) Seven Brief Lessons on Physics. London: Penguin Random House.

Russell B (1965) An Inquiry into Meaning and Truth. London: Penguin Random House.

Six Physics Equations that Changed the Course of History. Retrieved from https://bit. ly/2GzLZTJ.

Stockwell P (2006) Language and Literature: Stylistics. In B Aarts, A McMahon (Eds.), The Handbook of English Linguistics. London: Blackwell Publishing Ltd.

Ullmann S (1973) Meaning and Style. Oxford: Basil Blackwell. 
Wales K (1991) A Dictionary of Stylistics. Harlow and New York: Longman.

Widdowson HG (1992) Practical Stylistics. An Approach to Poetry. Oxford: Oxford University Press.

Widdowson HG (2010) Text, Grammar and Critical Discourse Analysis. In C Coffin, T Lillis, K O'Halloran (Eds.), Applied Linguistics Methods. A Reader. London and New York: Routledge. 